
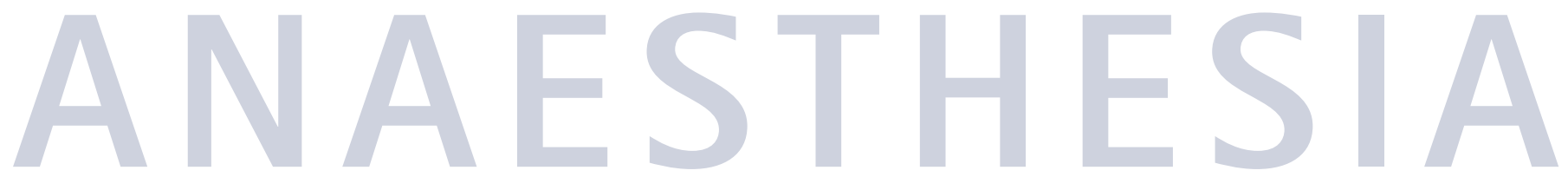

\section{Safety first}

Septodont claims modern invasive dentistry depends upon anaesthesia and what instrument to use during anaesthesia. To help dentists Septodont stock the Ultra Safety Plus XL.

Septodont claims the Ultra Safety Plus $\mathrm{XL}$ is a single use, safety syringe that is light in weight and easy to use. The needle has a 43\% larger internal bore which Septodont claims means the walls are thinner and dentists can get more anaesthetic through the needle with less pressure. This results in a far more comfortable experience for both patient and professional.

The Safety Plus is still the first and only system to be accredited by the BDA and now there is the U'SPinject handle which, when combined with UltraSafety Plus XL, enables dentists to carry out intraligamentary and intra-osseous injections that normally require strong pressure.

For more information phone 01622 686165.

Reader response number 58

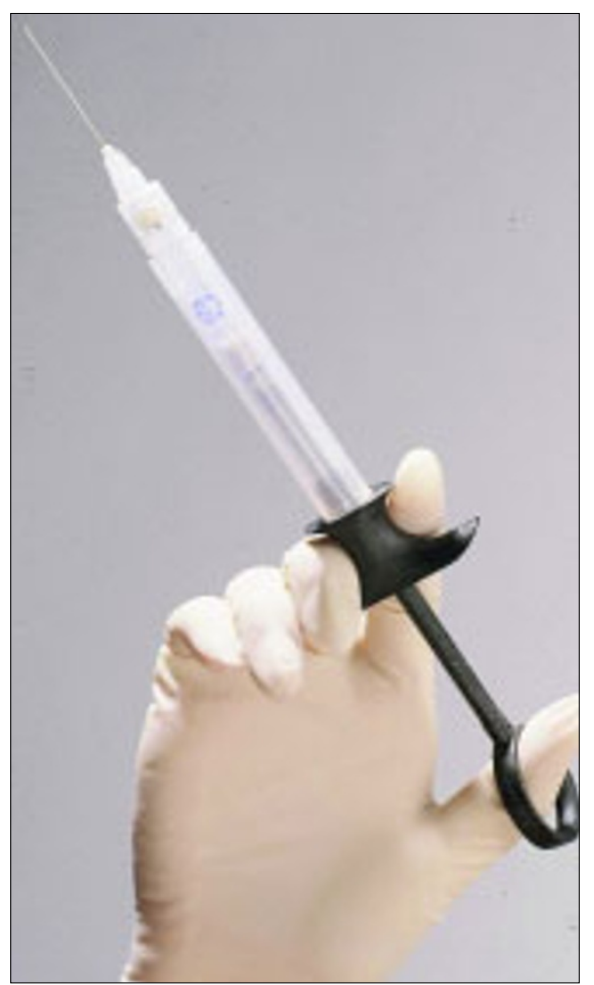

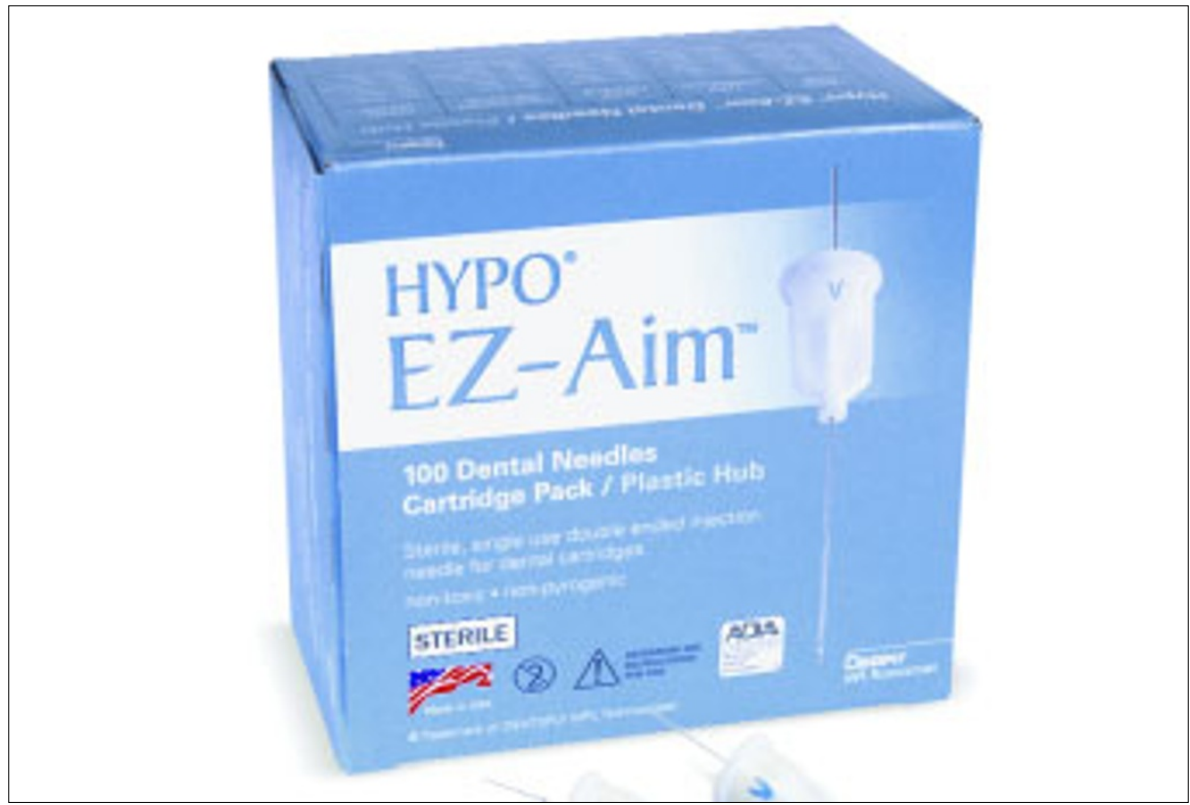

\section{The Hypo EZ-Aim from Dentsply}

It is no secret that patients do not like pain, so to help dentists give as painless anaesthesia by injection as possible Dentsply now supply the Hypo EZ-Aim. The Hypo EZ-Aim needles have been designed especially to reduce pain and make the procedure as comfortable as possible for the patient.

Dentsply claims testing also showed that the Hypo needles are 2 to 3 times more consistent than the other brands, meaning only the sharpest needles reach the surgery. Hypo EZ-Aim needles also now feature a bevel indicator, to aid correct needle insertion and drastically reduce the sensation of injection.

The Hypo EZ-Aim needles are available in a wide range of sizes (25, 27 and 30 gauge) with plastic hubs at a very competitive price. For a free sample, or more information phone 01932837275.

Reader response number 57

\section{Make your patients feel more relaxed}

Henry Schein says that as all dentists know, a lot of patients have a fear or dislike for needles. Using this information Henry Schein now supply the Injex, which is a needle free anaesthetic.

The Injex uses proven medical technology which Henry Schein claims is suitable for both children and adults and that patient stress is reduced as well. They also claim the Injex offers a number of advantages including an ampoule capacity of $0.3 \mathrm{ml}$, easy to sterilise and allows the dentist the option of using their personal, preferred choice of anaesthetic-load.

For more information phone 08700102043. Reader response number 59

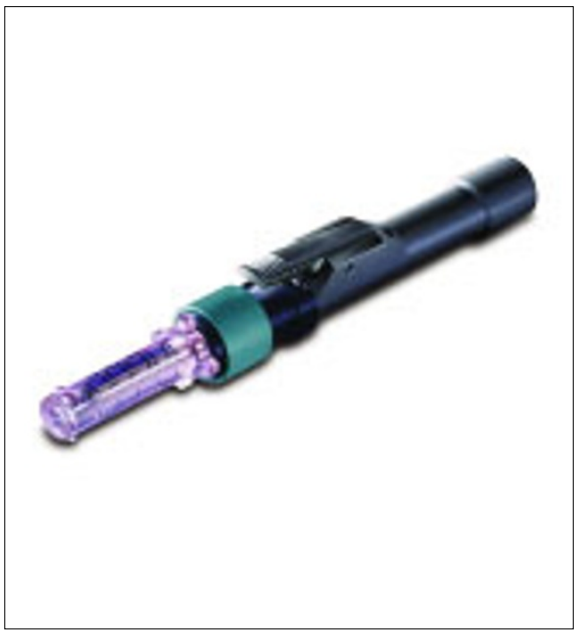

